Jie Zhang

Yang Liu

Han Zhang

https://doi.org/10.21278/TOF.43304

ISSN 1333-1124

eISSN 1849-1391

\title{
DESIGN AND MECHANICS ANALYSIS OF THE DEEP CAVITY TAPERED ROLLER THRUST BEARING USED IN A POSITIVE DISPLACEMENT MOTOR
}

\begin{abstract}
Summary
Positive Displacement Motor (PDM) is one of the most commonly used deep hole power drills. The thrust ball bearing unit is one of the vulnerable parts of the PDM. Failure of the thrust bearing greatly affects the PDM and can drastically reduce its drilling efficiency. In order to improve its service life, we have designed a new deep cavity tapered roller thrust bearing. In this analysis, we will evaluate the new product. In the past, results have shown that there is a serious stress concentration at both ends of the roller. The new deep cavity design will result in the improvement of the stress factor of tapered rollers. If the cavity depth and diameter are too small, the stress concentration at both ends of the roller becomes serious. If they are too large, the stress on the middle part of the roller is also too high. Deformation of the roller increases with an increase in the deep cavity's length and depth. Consequently, the deep cavity design can improve the PDM.
\end{abstract}

Key words: $\quad$ thrust bearing; deep cavity tapered roller; structure design; finite element method; contact mechanics

\section{Introduction}

The screw drill is one of deep hole drill motors and the thickness of the mud will actually determine how powerful the drill will be. As one of the most widely used drill motors, the PDM has a vital role in gas exploitation, geological exploration, architectural construction, national defense engineering and other drilling operations. The PDM is a kind of deep hole drill motor that can help improve the drilling rate, lower the pressure across the bit, and reduce wear and tear on the casing and the drilling tool. It also increases the penetration rate, accurately achieves deflection and angle drop and corrects the direction. Also, the PDM works as one unit consisting of many internal components.

As shown in Fig.1, a PDM consists of a bypass valve assembly, thread off prevention assembly, motor assembly, universal assembly and transmission shaft assembly. The transmission shaft assembly is the weakest section of all the parts and can easily break in some instances. Spindle fracture due to wear, connection thread erosion and breakage, bearing part damage and shell cracking can all lead to damage. The transmission shaft assembly contains a spindle shell, a transmission shaft, a thrust bearing group, a journal bearing and other auxiliary parts. 


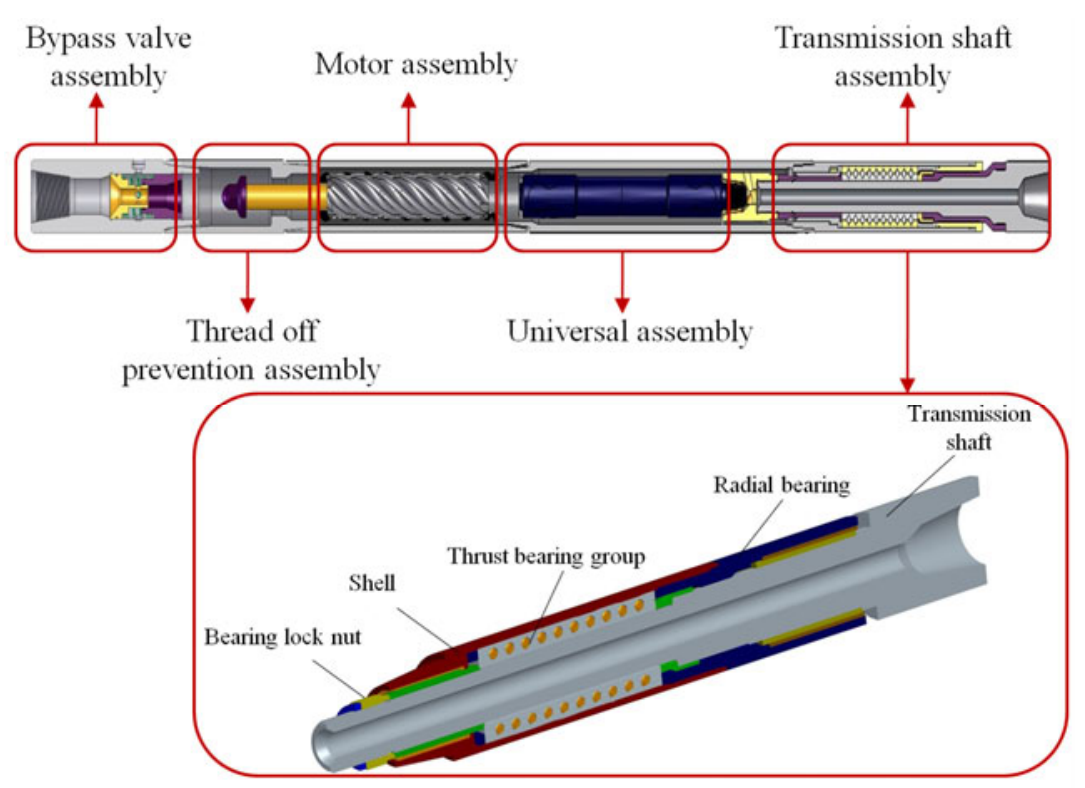

Fig. 1 Structure of drive shaft assembly

In many cases, four-point contact ball bearings are used in the PDM. The inner ring and the outer ring of the thrust ball bearings are fixed on the transmission shaft and the shell. The thrust ball bearing generates a minor diameter, high rotation speed and large load, which is different from the common design. The compact design makes it applicable to many drill sites. This is why the thrust ball bearing has been frequently used in the downhole drill motor. The screw drill assembly is considered as the weakest link in the transmission shaft. Although the thrust ball bearings are parts of the transmission shaft assembly, they would be the least damaged of all the screw drill parts. Namely, the screw drill is surrounded by a hostile environment. Also, the bearing supports heavy load and a wide range of alternating load. As a result, the ball and the ball track will be worn, even fractured (as shown in Fig. 2).

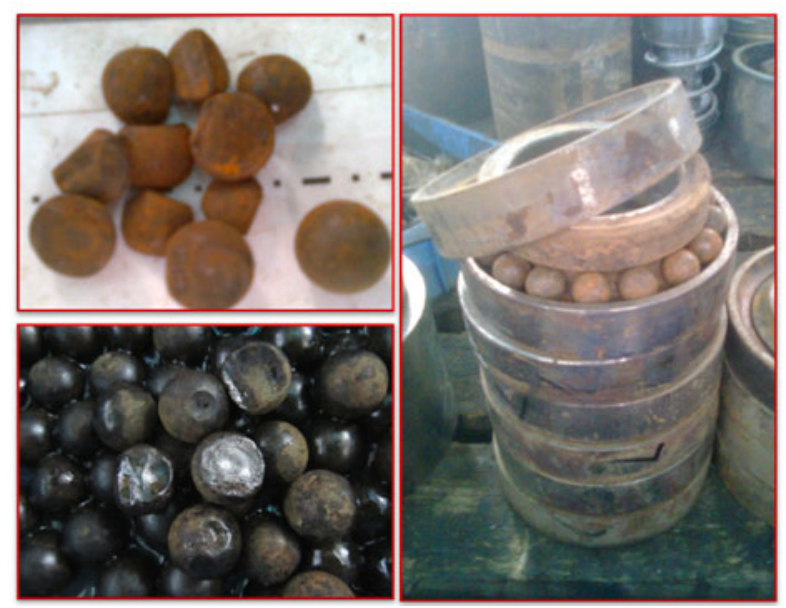

Fig. 2 Failure modes of the thrust ball bearing

Zhao investigated the method of designing a thrust ball bearing unit and found that the screw drill and the turbodrill worked well with the thrust ball bearing. Wang presented some improvements which increase the life of the transmission shaft and designed a kind of tapered roller bearing by analyzing the transmission shaft failure of the screw drill. Feng discussed the design of a common turbo-drill, thrust bearing group, stabilizing bearing group and other elements. Xu and Hua studied the equilibrating load mechanism of the four-point contact ball bearing of the turbo drill. They compared the design features and load distribution between 
the four-point contact ball bearing and the thrust radial ball bearing and revealed that the arc race ball bearings take the load well. Xie researched the material and technology of the turbodrill with a thrust bearing, and discussed the technology and the tribological properties of different bearing materials. The research provided a reference on how to select a material for thrust bearings. Zupan and Amasorrain set up a static model of the nonlinear function considering separately three and five independent variables. Zupan studied the four-point contact ball bearing under different actual contact angles considering the load capacity. Particularly, the actual contact angle is an equation of clearance, nominal contact angle, marginal adaptation and support of structure stiffness. He discussed and analyzed the deformation coordination of the geometrical structure of the ball bearing, and the variation distribution problem was related to the actual contact angle. Simultaneously, Zupan studied the rules of influence of the bearing support structure stiffness on the mechanical property of the bearing. Robert Kunc presented a digital design method and a numerical calculation model for the load capacity of the four-point contact ball bearing. From the model, the researcher achieved the elastic stress, the plastic stress and the real load capacity.

The bearing capacity of cylindrical and tapered roller bearings is larger than that of ball bearings. Ball bearings are prone to failure due to the stress concentration. In order to overcome this phenomenon, Zhang designed a deep cavity bearing to reduce stress concentration on the dens of the roller. Reusner and Fujiwara studied the logarithmic roller profile of cylindrical and taper roller bearings. We will demonstrate here a new design of a deep cavity tapered roller thrust bearing based on the preliminary research. Such a design can reduce the probability of the PDM breakdown.

\section{Tapered roller bearing}

In order to improve the service life of a PDM, it is necessary to improve the design of the four-point contact ball bearing attached to the transmission shaft assembly. Based on the traditional tapered roller thrust bearing and the transmission shaft, a new type of tapered roller thrust bearings was designed. It can be designed to reduce the stress on the rolling element and extend the service life.

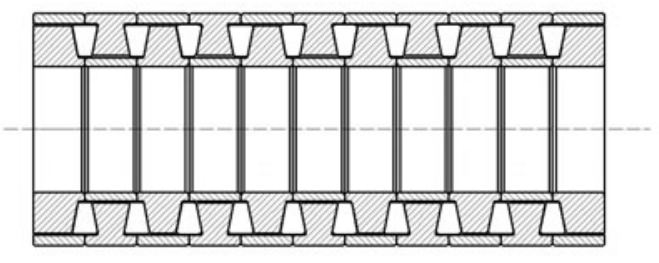

a. New thrust bearing group

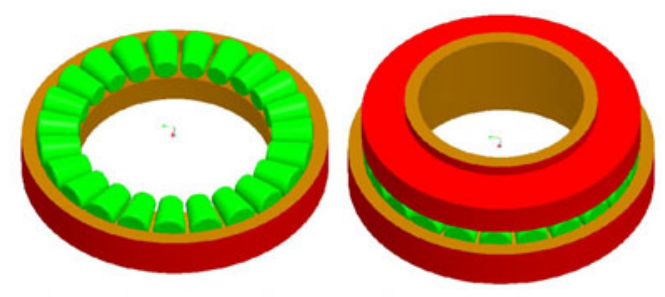

b. Thrust bearing components

Fig. 3 Tapered roller thrust bearings

Fig. 3 shows a schematic diagram and a tree-dimensional diagram of the new type of the tapered roller thrust bearing. The new bearing consists of an inner/outer ring of the bearing, a tapered roller, a holder and a sleeve. The rolling busbars of all tapered rollers meet 
at a point, which enables the tapered roller to make the pure rolling motion. The tapered roller replaces the ball. Then the point contact is changed to the line contact, which can enlarge the contact area between the rolling elements and the rollaway nest. This reduces the contact stress and improves the load capacity.

\section{Materials and methods}

Numerical simulation is an effective method for solving complex contact problems. The intuitive software called ADINA is used to solve bearing contact mechanical issues. Due to the structure of the tapered roller thrust bearing, the design of a single tapered roller is symmetrical too. As a result, a half model of the single tapered roller is established as shown in Fig. 4. In the element model, the bottom bearing plate is the inner ring of the thrust bearing, and the upper bearing plate is the outer ring. The constraints are applied to the underside of the inner ring. An exception is the direction of the transmission shaft. To simulate the load in the axial direction, the uniform load of $9.474 \mathrm{MPa}$ is applied to the outer ring.

A hexahedral element is used for meshing the rollers' upper and bottom plates. This will improve the computational accuracy. It is also necessary to refine the mesh at the contact area. Two contact pairs are included in this model. First, one must set up a contact pair for the outer surface of the tapered roller with respect to the upper surface of the inner ring and the bottom surface of the outer ring. Explicit dynamics is used for the contact analysis. Penalty function is used for the contact algorithm. Simultaneously, the friction coefficient is 0.2 between the tapered roller and the inner and the outer ring. Also, the elasticity modulus of the bearing material is $210 \mathrm{GPa}$, the Poisson ratio is 0.3 , and the density is $7800 \mathrm{~kg} / \mathrm{m}^{3}$.

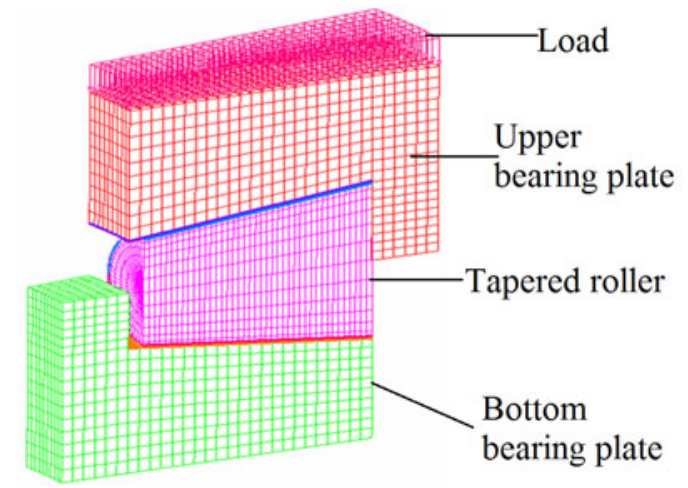

Fig. 4 Finite element model of the tapered roller thrust bearing

\section{Simulation results}

Fig. 5 shows the contact stress and the equivalent stress of the thrust bearing. The contact width of the stress distribution gradually increases from the small end to the large end of the tapered roller. The highest contact stress appears at the large end of the roller. The larger equivalent stress occurs merely at the contact area of the tapered roller, while the stress on the other parts is low. An equal stress also appears at the contact area of the inner and outer rings that are in contact with the tapered roller.

In the stress analysis of the tapered roller, the stress distribution curves along the axial direction are shown in Fig. 5. The stress exerted on both ends of the tapered roller is higher than that exerted on the middle section. There is a serious stress concentration phenomenon. Particularly, the equivalent stresses exerted on both ends are higher than the contact stress. The stress distribution in the middle part of the tapered roller is uniform. However, the value increases gradually from the small end to the large end of the tapered roller. 


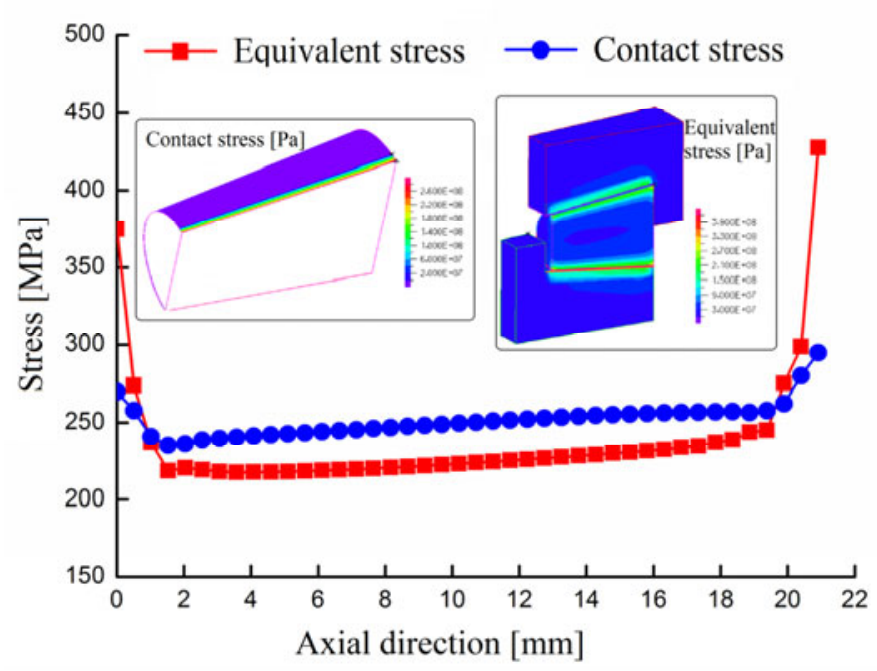

Fig. 5 Contact stress and equivalent stress of the roller

\section{Design of the deep cavity tapered roller bearing}

The stress concentration phenomenon is called "edge effect". It occurs at both ends of the tapered roller. The edge effect can result in fatigue failure at both ends of the tapered rollers. To solve and eliminate this, only one kind of deep cavity tapered roller bearings is applicable. The contact stiffness of both ends of the tapered roller of this design is lower than that of the middle part. When the tapered roller is in contact with the inner ring and the outer ring, it will relieve the stress concentration phenomenon because of the deformation at both ends.

As shown in Fig. 6, the deep cavity tapered roller is designated for this position. Both sides of the tapered roller are processed into the deep cavity structure. The depth of the deep cavity is $h$ and the radius of the deep cavity is $r$. This deep cavity tapered roller can reduce and even eliminate the stress concentration phenomenon and enhance the load bearing capacity of the roller. At the same time, the load bearing strength and fatigue life will improve effectively.

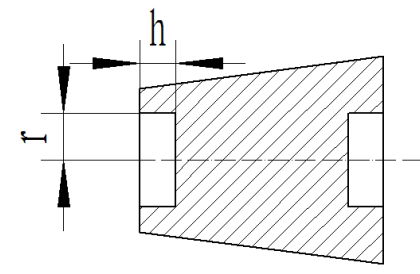

Fig. 6 Deep cavity tapered roller

\section{Results and discussion}

\subsection{Deep cavity length}

The deep cavity radius of the large end of the tapered roller is $6 \mathrm{~mm}$. The diameter of the small end is $4 \mathrm{~mm}$. Fig. 7 shows an equivalent stress distribution of the deep cavity tapered roller with different deep cavity depths. When the depth is $1 \mathrm{~mm}$, the maximum equivalent stress of the roller appears at the large end. When the deep cavity depth is greater than $1 \mathrm{~mm}$, the maximum equivalent stress of the roller appears in the middle part, while the stress values are lower at both ends. This indicates that the deep cavity design has reduced the stress concentration phenomenon in the tapered roller. 


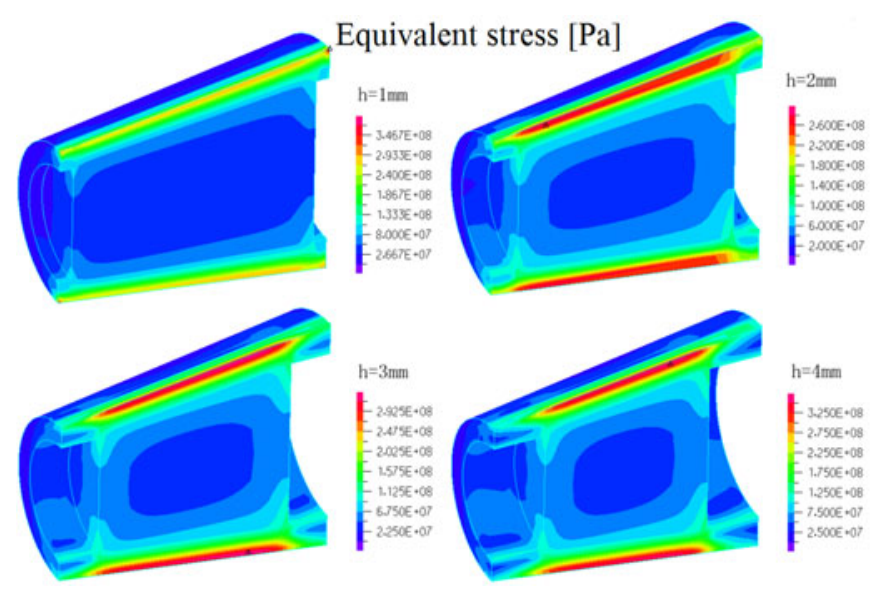

Fig. 7 Equivalent stress of the tapered roller

Fig. 8 shows equivalent stress curves of the tapered roller with different deep cavity depths. The stress concentration appears on the solid roller and the deep cavity roller with a depth of $1 \mathrm{~mm}$. The equivalent stress at the ends when the deep cavity depth is $1 \mathrm{~mm}$ is less than that of the solid roller. However, the stress exerted on the middle part of the deep cavity roller is higher than that exerted on the solid roller, which shows that the deep cavity design can reduce the stress at both ends effectively. When the deep cavity depth increases, the equivalent stress at both ends of the tapered roller decreases while the stress on the middle part increases. Consequently, it is not unreasonable to increase the deep cavity depth unlimitedly. The results demonstrate that the appropriate depth is $1 \mathrm{~mm}$ to $2 \mathrm{~mm}$. The tapered roller suffers a serious stress concentration when the smaller depth is too small. When the cavity depth is too large, the stress concentration appears in the middle part of the bearing.

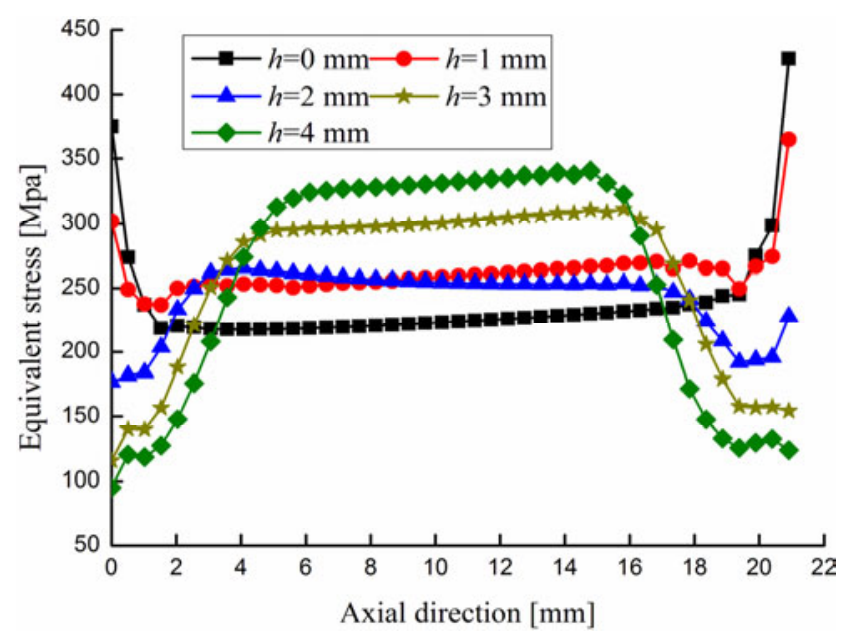

Fig. 8 Equivalent stress of the roller with different cavity depths

Fig. 9 shows the contact stress distribution in the deep cavity tapered roller. The contact stress distribution in the middle part of the deep cavity tapered roller is larger than at its ends. The deep cavity improves the edge effect in the solid tapered roller. As the cavity depth increases, the contact stresses at both ends decrease and the contact stress in the middle part of the tapered roller increases gradually. 


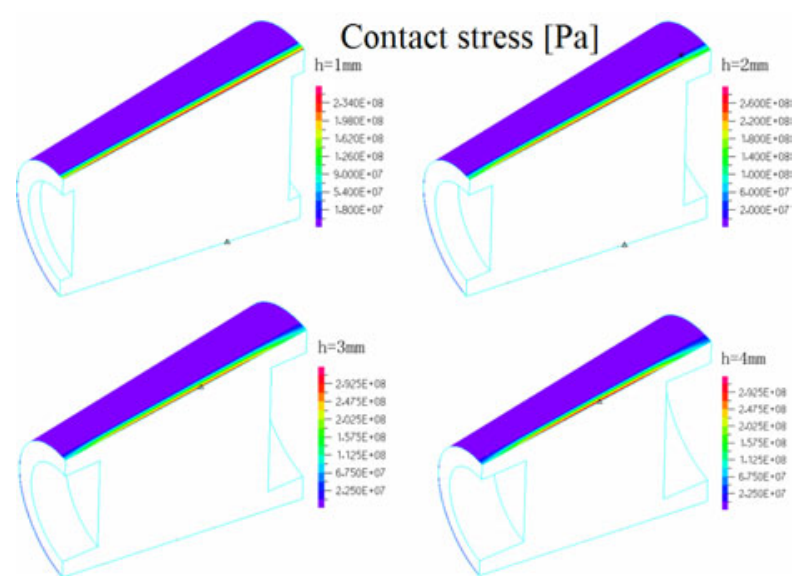

Fig. 9 Contact stress on the roller with different cavity depths

Fig. 10 shows the contact stress curves of the tapered roller with different cavity depths. The contact stress at both ends of the solid roller is high while that in the middle part of the roller is equally distributed. The contact stress at both ends of the deep cavity roller is low while that in the middle part is high. As the cavity depth increases, the contact stresses at both ends of the tapered roller reduce gradually while the stress in the middle part increases. The contact stress of the deep cavity roller is higher than that of the solid roller, which indicates that the deep cavity design can improve the contact stress distribution and enlarge the contact stress in the middle part. Consequently, the contact stress distribution does not improve as the depths become larger.

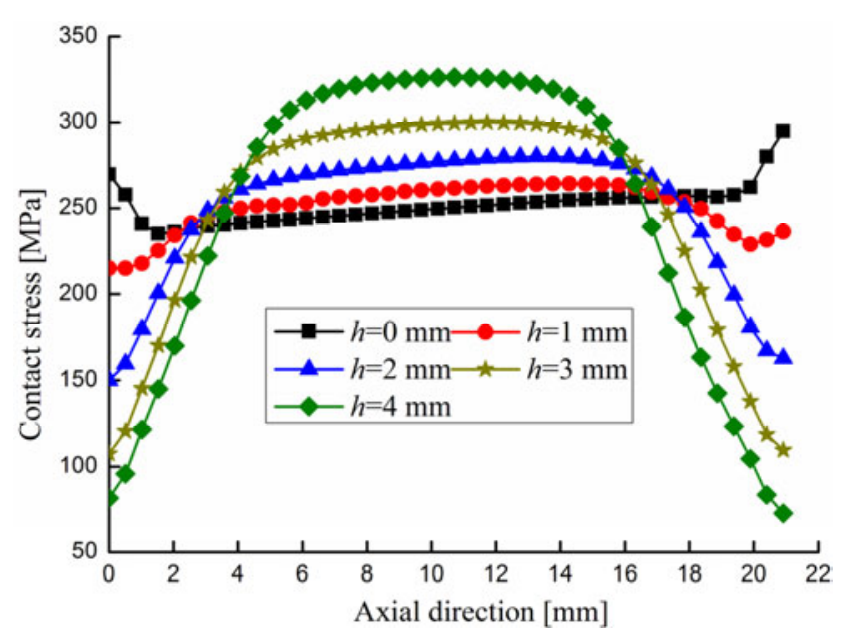

Fig. 10 Contact stress curves of the roller with different cavity depths

The deformation along the axial direction of the deep cavity tapered roller is shown in Fig. 11. It is evident that the tapered rollers with different cavity depths follow a similar displacement distribution rule. The displacements of both ends are greater than those of the middle part. As the depth of the deep cavity increases, the displacement of the large end increases gradually. In such a circumstance, due to the increase in the cavity depth, the contact stiffness at both ends is lower. As a result, both ends of the roller tend to be deformed. 


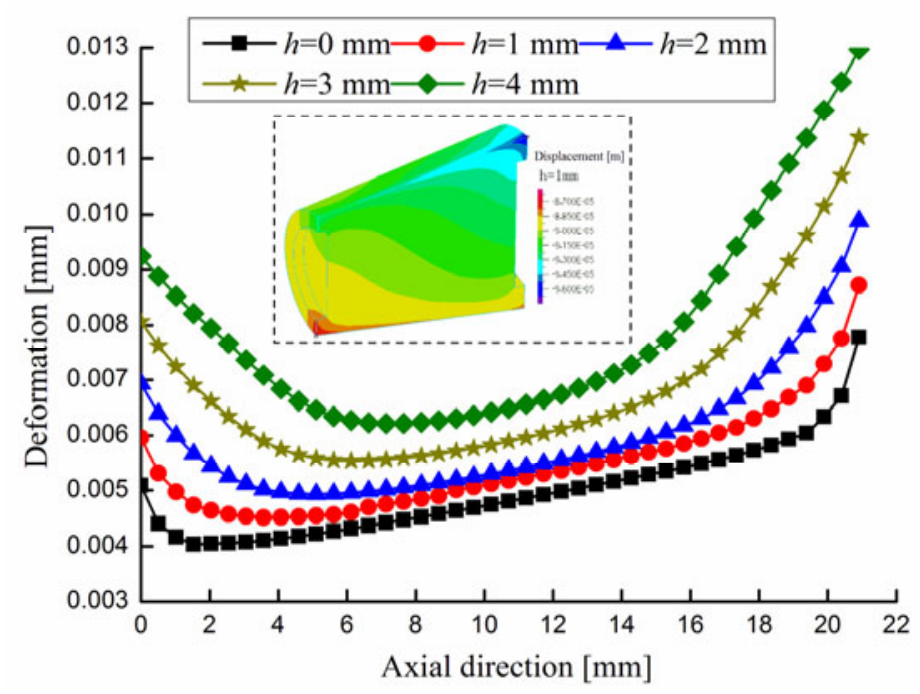

Fig. 11 Deformation curves of the roller with different deep cavity depths

The deformation of the large end is greater than that of the smaller end. The deformation of both ends is greater than that of the middle part. As the depth increases, the deformation of the roller increases and the edge effect becomes more apparent. The total deformation of the roller increases irregularly. The premature failure will occur at both ends if the deformation of the tapered roller is uneven. In conclusion, it is vital to control the cavity depth to prevent excessive deformation.

Table 1 Simulation results for the roller with different deep cavity depths

\begin{tabular}{|c|c|c|c|c|c|c|c|c|c|c|}
\hline \multirow{2}{*}{$\begin{array}{c}\text { Depth/ } \\
\mathrm{mm}\end{array}$} & \multicolumn{2}{|c|}{$\begin{array}{c}\text { Outer ring equivalent } \\
\text { stress }\end{array}$} & \multicolumn{2}{|c|}{$\begin{array}{c}\text { Inner ring equivalent } \\
\text { stress }\end{array}$} & \multicolumn{2}{c|}{$\begin{array}{c}\text { Roller equivalent } \\
\text { stress }\end{array}$} & \multicolumn{2}{c|}{ Contact stress } & \multicolumn{2}{c|}{ Roller deformation } \\
\cline { 2 - 12 } & $(\mathrm{MPa})$ & $\begin{array}{c}\text { Reduction } \\
\text { rate (\%) }\end{array}$ & $\begin{array}{c}(\mathrm{MPa}) \\
\text { ) }\end{array}$ & $\begin{array}{c}\text { Reduction } \\
\text { rate (\%) }\end{array}$ & $(\mathrm{MPa})$ & $\begin{array}{c}\text { Reduction } \\
\text { rate (\%) }\end{array}$ & (MPa) & $\begin{array}{c}\text { Reduction } \\
\text { rate (\%) }\end{array}$ & (mm) & $\begin{array}{c}\text { Reduction } \\
\text { rate (\%) }\end{array}$ \\
\hline 0 & 215.2 & 0 & 198.8 & 0 & 425.7 & 0 & 290.0 & 0 & 0.00777 & 0 \\
\hline 1 & 203.6 & 5.39 & 204.9 & -3.07 & 364.6 & 14.35 & 265.7 & 8.38 & 0.00872 & -12.1 \\
\hline 2 & 209.6 & 2.60 & 211.5 & -6.39 & 277.4 & 34.84 & 280.5 & 3.28 & 0.00988 & -27.1 \\
\hline 3 & 220.5 & -2.46 & 221.9 & -11.6 & 330.4 & 22.39 & 299.8 & -3.38 & 0.01139 & -46.5 \\
\hline 4 & 236.3 & -9.80 & 238.1 & -19.8 & 361.2 & 15.15 & 326.3 & -12.5 & 0.01297 & -66.8 \\
\hline
\end{tabular}

Table 1 shows the results for all parts for the tapered roller thrust bearing with different cavity depths. Equivalent stresses of the inner and the outer ring increase with an increase in the cavity depth. The equivalent stress of the tapered roller first decreases and then increases while the cavity depth increases. The equivalent stress of the tapered roller reaches its minimum value when the cavity depth is $2 \mathrm{~mm}$. As the cavity depth increases, the contact stress of the tapered roller becomes increasingly magnified. When the cavity depth is greater than $3 \mathrm{~mm}$, the contact stress of the deep cavity tapered roller is greater than that of the solid roller. As a result, the deformation of the roller increases with an increase in the cavity depth.

\subsection{Deep cavity diameter}

When the cavity depth of the roller is $3 \mathrm{~mm}$, the equivalent stress of the tapered roller with different deep cavity diameters is as shown in Fig. 12. In Fig. 12, $r_{1}$ is the radius of the small end of the deep cavity and $r_{2}$ is the radius of the large end. For example, $r_{1}=1 \mathrm{~mm}$ and $r_{2}=1.5 \mathrm{~mm}, r_{1}=2 \mathrm{~mm}$ and $r_{2}=3 \mathrm{~mm}, r_{1}=3 \mathrm{~mm}$ and $r_{2}=4.5 \mathrm{~mm}, r_{1}=4 \mathrm{~mm}$ and $r_{2}=6 \mathrm{~mm}$, $r_{1}=5 \mathrm{~mm}$ and $r_{2}=7.5 \mathrm{~mm}$. Fig. 12 shows that the first three types of rollers have the maximum equivalent stress at the large end. On the other hand, the maximum equivalent stress appears in the middle part of the last two rollers, and the smaller equivalent stress 
appears at the both ends. It is apparent that the larger the cavity diameter is, the smaller the stress at both ends becomes. The whole roller has a uniform stress distribution.

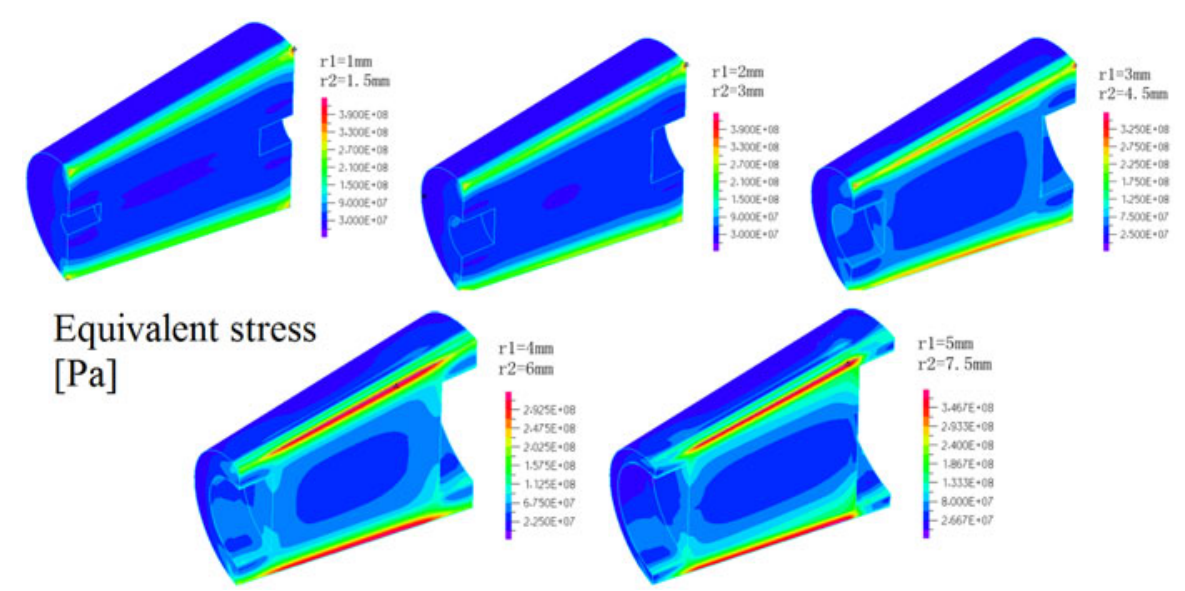

Fig. 12 Equivalent stress of the roller with different deep cavity radii

Fig. 13 shows equivalent stress curves of the roller with different deep cavity radii. When $r_{1}$ ranges from 0 to $3 \mathrm{~mm}$, the tapered rollers have a similar equivalent stress distribution and the stress concentration at both ends will be unapparent when the cavity radius increases. When $r_{1}$ changes from $4 \mathrm{~mm}$ to $5 \mathrm{~mm}$, the equivalent stress exerted on the tapered rollers presents a "W"-shaped figure. When the cavity diameter increases, the stress at both ends decreases, but the stress in middle part increases. Furthermore, if the roller has a larger deep cavity diameter, the middle part will have a higher equivalent stress. In conclusion, it is appropriate that the roller with a diameter of $3 \sim 4 \mathrm{~mm}$ is used.

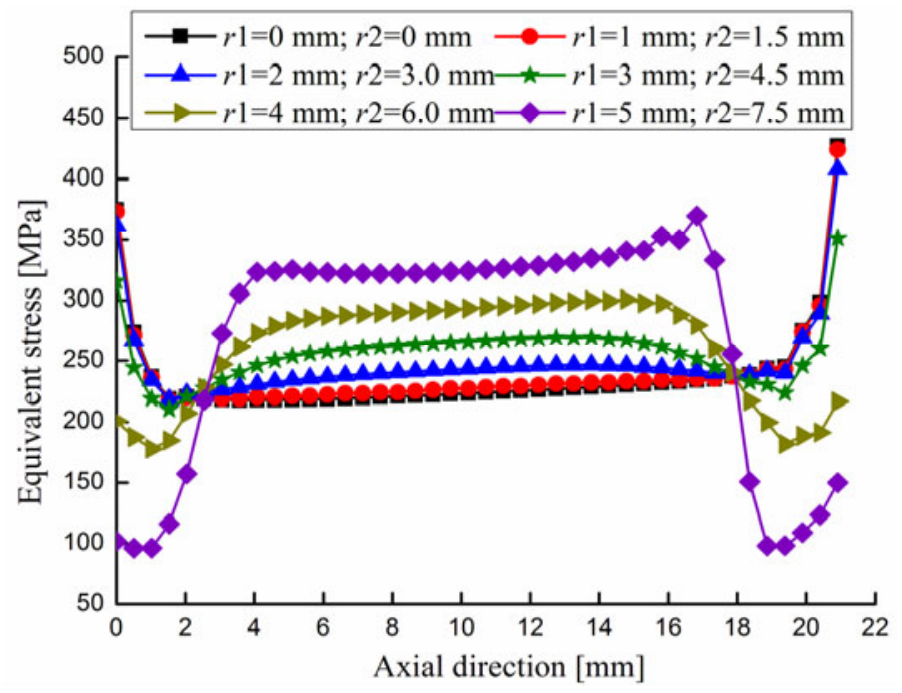

Fig. 13 Equivalent stress curves of the roller with different deep cavity radii

Fig. 14 shows the contact stress of the tapered roller with different cavity radii. When $r_{1}=1 \mathrm{~mm}$ and $r_{2}=2 \mathrm{~mm}$, the maximum contact stress of the tapered roller appears at the large end. The contact stress increases gradually from the small end to the large end. When $r_{1}$ is greater than $3 \mathrm{~mm}$, the maximum contact stress at the tapered roller exists in the middle part. However, both ends have a lower stress. In other words, the contact stress at both ends will be lower when the deep cavity radius increases. 


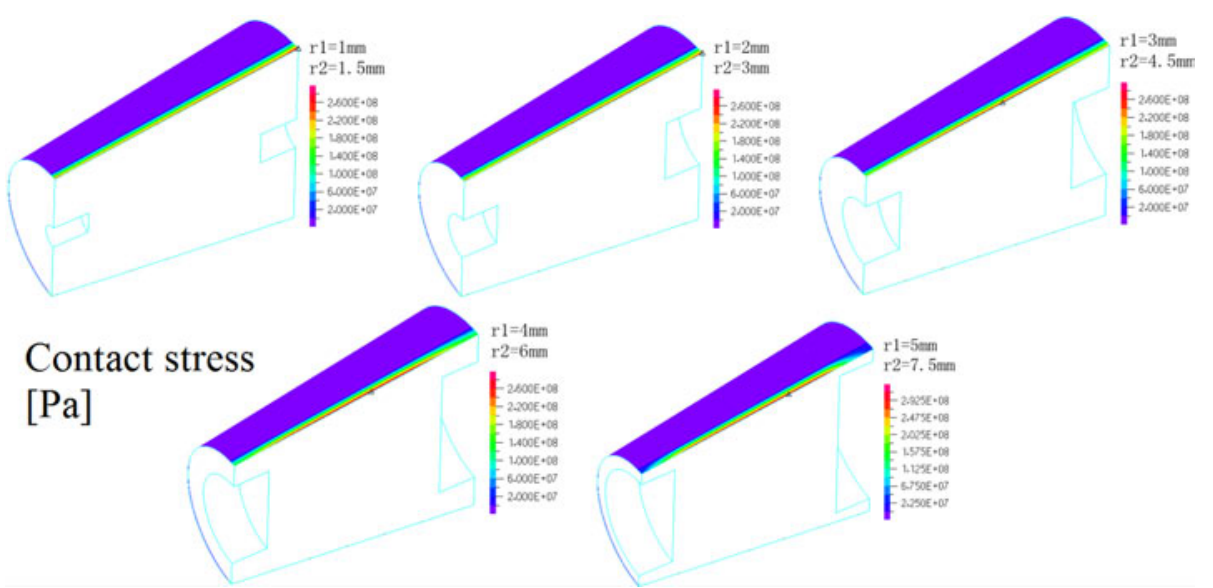

Fig. 14 Contact stress of the roller with different deep cavity radii

Fig. 15 shows the contact stress curves of the roller with different cavity radii. When the cavity radius is less than $2 \mathrm{~mm}$, there is a small chance for the contact stress distribution in the tapered roller. When the deep cavity radius is greater than $2 \mathrm{~mm}$, the contact stress at both ends decreases, while that of the middle part increases gradually. The larger the deep cavity roller radius is, the smaller the contact stress at both ends is. If $r_{1}$ exceeds $5 \mathrm{~mm}$, the contact stresses at both ends will be less than $50 \mathrm{MPa}$, and the middle part will maintain a value above $300 \mathrm{MPa}$. The edge effect on both ends decreases and can affect the strength of the roller no matter whether the contact stress at both ends is low or high. Therefore, in order to reduce the stress changes at both ends, the contact stress along the general direction should be equal.

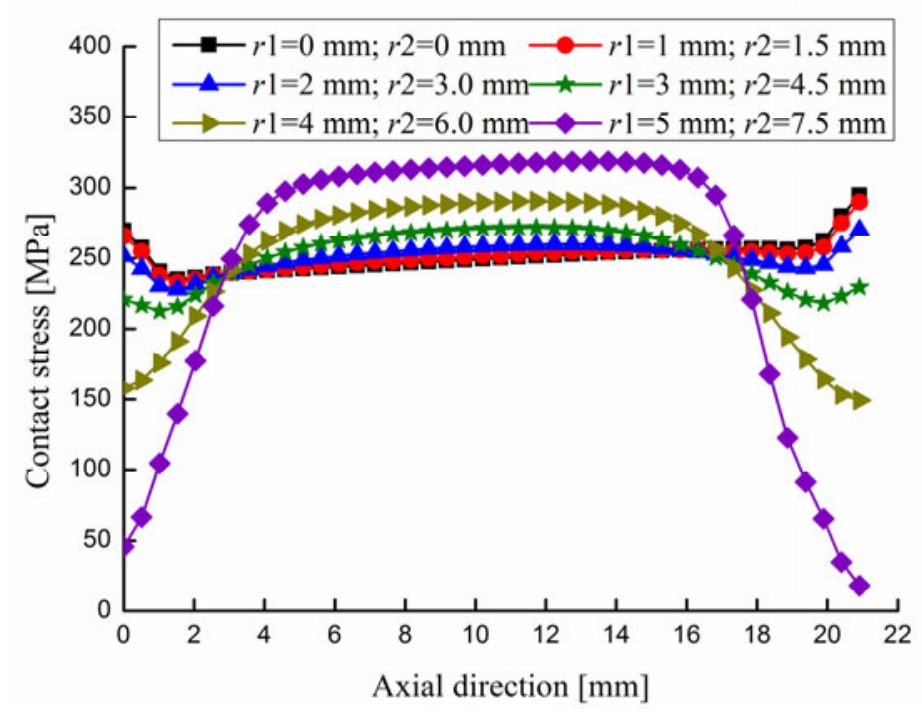

Fig. 15 Contact stress curves of the roller with different deep cavity radii

Fig. 16 shows the displacement contour and deformation curves of the deep cavity tapered roller. Different rollers have a similar distribution rule. Deformation of both ends is larger than that of other parts. The larger the deep cavity roller radius is, the larger the displacement at both ends will be. As the deep cavity radius increases, the deformation of the roller is larger. The edge effect will be obvious when the deformation at both ends increases. From the roller, the deformation of the large end of the deep cavity tapered roller is greater than that of the small end. So, the larger the deep cavity diameter, the more non-uniform the deformation of the roller is. 


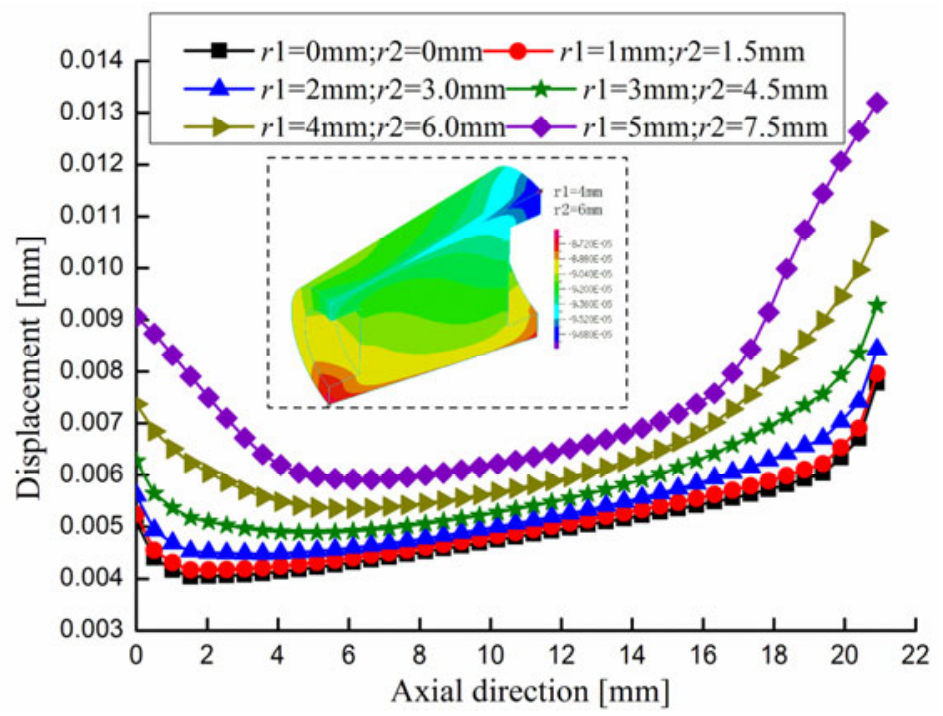

Fig. 16 Deformation curves of the roller with different deep cavity radii

The calculated results of the tapered roller thrust bearing with different deep cavity radius units are shown in Table 2. As the tapered roller's deep cavity radius increases, the equivalent stresses on the inner and outer rings first decrease and then increase. When $r_{1}$ is $3 \mathrm{~mm}$, the equivalent stresses of the inner and outer rings approach the minimum value. The equivalent stress and the contact stress of the tapered roller will first decrease and then increase as the deep cavity radius increases gradually. When $r_{1}$ is $2 \mathrm{~mm}$, the equivalent stress of the roller approaches the minimum value, but the deformation of the tapered roller will be larger as the deep cavity radius increases gradually. When $r_{1}$ is $5 \mathrm{~mm}$, the maximum deformation of the tapered roller increases by $69.8 \%$.

Table 2 Simulation results of the roller with different deep cavity radii

\begin{tabular}{|c|c|c|c|c|c|c|c|c|c|c|}
\hline \multirow{2}{*}{$\begin{array}{c}\text { Radius } \\
\text { /mm }\end{array}$} & \multicolumn{2}{|c|}{$\begin{array}{c}\text { Outer ring equivalent } \\
\text { stress }\end{array}$} & \multicolumn{2}{|c|}{$\begin{array}{c}\text { Inner ring equivalent } \\
\text { stress }\end{array}$} & \multicolumn{2}{c|}{$\begin{array}{c}\text { Roller equivalent } \\
\text { stress }\end{array}$} & \multicolumn{2}{c|}{ Contact stress } & \multicolumn{2}{c|}{ Roller deformation } \\
\cline { 2 - 12 } & $(\mathrm{MPa})$ & $\begin{array}{c}\text { Reduction } \\
\text { rate (\%) }\end{array}$ & $\begin{array}{c}(\mathrm{MPa}) \\
\text { ) }\end{array}$ & $\begin{array}{c}\text { Reduction } \\
\text { rate (\%) }\end{array}$ & (MPa) & $\begin{array}{c}\text { Reduction } \\
\text { rate (\%) }\end{array}$ & (MPa) & $\begin{array}{c}\text { Reduction } \\
\text { rate (\%) }\end{array}$ & (mm) & $\begin{array}{c}\text { Reduction } \\
\text { rate (\%) }\end{array}$ \\
\hline 0 & 215.2 & 0 & 198.8 & 0 & 425.7 & 0 & 290.0 & 0 & 0.00777 & 0 \\
\hline 1 & 234.4 & -8.92 & 209.7 & -5.48 & 423.7 & 0.47 & 289.5 & 0.17 & 0.00796 & -2.39 \\
\hline 2 & 222.4 & -3.35 & 200.1 & -0.65 & 407.5 & 4.28 & 269.8 & 6.97 & 0.00843 & -8.43 \\
\hline 3 & 200.4 & 6.88 & 202.4 & -1.81 & 352.0 & 17.3 & 271.7 & 6.31 & 0.00928 & -19.3 \\
\hline 4 & 213.5 & 0.79 & 215.1 & -8.20 & 330.1 & 22.5 & 290.5 & -0.17 & 0.01073 & -38.0 \\
\hline 5 & 236.9 & -10.1 & 237.4 & -19.4 & 390.0 & 8.39 & 318.9 & -9.97 & 0.01320 & -69.8 \\
\hline
\end{tabular}

\section{Conclusion}

As shown, the thrust ball bearing group is one of the weakest parts of the positive displacement motor. In order to overcome the failure problem of four-point contact ball bearings, a new tapered roller thrust bearing is designed. At both ends of the tapered roller the stress concentration called "edge effect" occurs, which affects the bearing strength and service life of the roller greatly. The stress distribution in the middle part of the roller is more uniform. The deep cavity tapered roller thrust bearing was designed as a deep cavity structure that can effectively improve the stress concentration of tapered rollers. The stress concentration at both ends of the roller is still a serious concern when the cavity depth and diameter are too small. If the cavity depth and diameter are too large, the stress exerted on the middle part of the roller is high. The deformation of the roller increases with an increase in the length and depth of the deep cavity. The research results can provide a scientific basis for an optimal design and manufacture of tapered rollers. 


\section{ACKNOWLEDGMENTS}

This study was supported by the State Key Laboratory for Mechanical Transmissions (No. SKLMT-KFKT-201611), Luzhou Science and Technology Project (No. 2018-GYF-6) and Chengdu Science and Technology Project (No. 2019-GH02-00072-HZ).

\section{REFERENCES}

[1] Zhao N. :Research on design method of rolling bearings in power drills. Drilling Production Technology, 20(2):38-42, 1997

[2] Wang J.T, Tan C.F., WangL.P. et al.: Failure analysis and improvement of life-span measures for screw shaft drive shaft. West-China Exploration Engineering, (5): 57-59, 2010

[3] Feng D.: Domestic turbine drilling tool structure and performance analysis. China Petroleum Machnery, 35(1):59-61, 2007

[4] Xu F.D, Hua B.Z.: Mechanism of average distribution of load for four points contact ball bearing in the turbodrill. Mining \& Processing Equipment, 27(12):19-20,1999.

[5] Xie J.W., Zhou D.J., Jia W.J.: Turbine drill roller thrust bearing materials and suggestions for its process. Oil Field Equipment, 28(5):43-46, 1999

[6] Zupan S., Prebil I.: Carring angel and capacity of a large single row hall bearing as a function of geometry parameter of the rolling contact and the supporting structure stiffness. Mechanism and Machine Theory, (36):1087-1103, 2001. https://doi.org/10.1016/s0094-114x(01)00044-1

[7] Jose Ignacio Amasorrain, Xabier Sagartzazu, Jorge Damian.: Load distribution in a four contact point slewing bearing. Mechanism and Machine Theory, 38: 479-496,2003.

https://doi.org/10.1016/s0094-114x(03)00003-x

[8] Robert Kunc, Ivan Prebil.: Numerical determination of carrying capacity of large rolling bearings. Journal of Materials Processing Technology, 155-156: 696-1703, 2004. https://doi.org/10.1016/j.jmatprotec.2004.04.125

[9] Zhang, J., Liang, Z, Han, C.J.: Optimization design of deep cavity cylindrical roller based on FEM and RSM. Chinese Journal of Computational Mechanics,32,307-312,2015.

[10] Reusner, H.:The logarithmic roller profile-the key to superior performance of cylindrical and taper roller bearings. Ball Bearing J., 230, SKF, June 1987.

[11] Fujiwara, H. Kawase, T.: Logarithmic Profiles of Rollers in Roller Bearings and Optimization of the Profiles, NTN Technical review,75, 2007.

[12] Zhang J., Xiao Y., Liang Z.: Mechanical Behaviors and Failure Mechanisms of Buried Polyethylene Pipes Crossing Active Strike-slip Faults. Composites Part B: Engineering,154,449-466, 2018. https://doi.org/10.1016/j.compositesb.2018.09.006

[13] Zhang J., Xie J.X., Liu X.L.: Numerical evaluation of heat extraction for EGS with tree-shaped wells. International Journal of Heat and Mass Transfer,134, 296-310. https://doi.org/10.1016/j.ijheatmasstransfer.2018.12.171

[14] Zhang J., Xie R.: Mechanical response analysis of the buried pipeline due to adjacent foundation pit excavation. Tunnelling and Underground Space Technology,78, 135-145, 2018. https://doi.org/10.1016/j.tust.2018.04.026

Submitted: $\quad 11.4 .2018$

Accepted: $\quad$ 27.3.2019
Jie Zhang

1.The State Key Laboratory of Mechanical Transmissions, Chongqing University, Chongqing, 400044, China

2. School of Mechatronic Engineering, Southwest Petroleum University, Chengdu 610500, China

E-mail: longmenshao@163.com

Yang Liu

Han Zhang

School of Mechatronic Engineering

Southwest Petroleum University,

Chengdu, China, 610500 